\title{
Research on Influencing Factors of Reservoir Construction Risk Based on Interpretative Structural Modeling
}

\author{
Wang Xin, Yueming Wang \\ School of Civil Engineering and Architecture, Southwest University of Science and Technology, Mianyang, China \\ Email: 1064123527@qq.com
}

How to cite this paper: Xin, W. and Wang, Y.M. (2021) Research on Influencing Factors of Reservoir Construction Risk Based on Interpretative Structural Modeling. World Journal of Engineering and Technology, 9, 727-736.

https://doi.org/10.4236/wjet.2021.94049

Received: August 10, 2021

Accepted: September 11, 2021

Published: September 14, 2021

Copyright $\odot 2021$ by author(s) and Scientific Research Publishing Inc. This work is licensed under the Creative Commons Attribution International License (CC BY 4.0).

http://creativecommons.org/licenses/by/4.0/

\begin{abstract}
Reservoir plays an important role in the allocation and rational use of water resources, especially water resources in China are centrally distributed in the western region, and large reservoirs should be built to meet the people's livelihood needs of each region. The construction of large reservoirs has numerous risks, the clarity of these risks helps us to better plan and make decisions before implementing the project. Search through literature reading and professional information, determined 11 risk factors in the construction phase of the reservoir construction project case, construct a risk influencing factor system under the application of ISM (Interpretative Structural Modeling). Studies have shown that the risks of strategic guidelines and policies and changes in infrastructure planning have the deepest impact on construction risk management. Among them, the strategic policy risk is the root impact, and the impact of the infrastructure planning change risk has a far-reaching impact. Through the above conclusions, providing management countermeasures and suggestions for the risk control of reservoir construction.
\end{abstract}

\section{Keywords}

ISM, Reservoir Project, Construction Stage, Risk Management, Influencing Factors

\section{Introduction}

The construction stage is the most important stage for the actual implementation of a project. In this stage, the cost, quality, and safety management of the project play a decisive role in the overall operation. With the development of the construction industry toward mechanization, intelligentialize, and assemblage, 
the gradual transparency of cost and quality makes the key issues of the project focus on safety management. From the person in charge of the project to the first-line construction personnel, if you want to grasp the safety and quality pass, you must first understand the risk factors that may occur during the construction process, so as to better carry out construction and production, realizing the economic benefits of the project [1] [2].

With the continuous development of our country's construction technology, bridge projects are constantly developing towards large-span, heavy-duty, and high-speed characteristics [3], and housing construction projects are constantly advancing in the direction of super high-rises and irregular shapes. The difficulty of construction safety management follows technological progress. It is also gradually improving. A large number of scholars have conducted investigations on the construction risks of these projects [4]. Although the prefabricated engineering that has emerged in recent years is highly mechanized and intelligent, there may still be quality and safety risk factors in the construction process. Scholars such as Li Songchen use the analytic hierarchy process and the ABC classification method [5] [6] to classify the risk factors the project exists, sorted and evaluated to help project managers at all levels grasp key risks and improve the effectiveness of project risk management and control. Duan Yonghui, Yang Siling, Wu Xi [7] [8] [9] and others used structural equation modeling (SEM), particle swarm optimization, structural entropy weight and modified evidence theory to study the main factors affecting the safety of prefabricated building construction, which provides a reference for the safety risk assessment of prefabricated building construction. The coupling of VPRS (Variable Precision Rough Set) and APH improves the practicability and effectiveness of construction's safety risk assessment [10]. In addition, the introduction of the Internet of Things and cloud computing has made the operation of risk factor identification, evaluation, early warning and pre-control systems more convenient [11]. Based on ANPFUZZY, Hua Weijie et al. identified and monitored the source of risk at the construction site, which made it much more accurate than using the Analytic Hierarchy Process model [12]. Yang Liqiong [13] etc assessment construction safety risk assessment methods based on BDD (binary decision diagram) provide a scientific basis for identifying the main influencing factors of project safety risks.

Although previous studies by scholars have almost clarified the general types of risk factors in the construction process and issued a series of monitoring, early warning, and prevention measures, there are few previous studies to ascertain the factors that cause safety accidents, as well as the primary and secondary relationship or the deep-seated influence between them. Therefore, this article selects the case of the Lijiayan Reservoir Project in Chengdu in various aspects of management during the construction phase and uses ISM (Interpretive Structure Model) to simplify the relationship between the elements, so that the direct and indirect factors are clear at a glance, and it is better for decision-makers to find specific ways and restrain or reduce the loss caused by the risks. 


\section{Analysis of Influencing Factors in Reservoir Construction Process}

\subsection{Introduction of Project}

The dam site of the Chengdu Lijiayan Reservoir Project is about 1.3 kilometers upstream of the Qingfengling Bridge in Huaiyuan Town, Chongzhou City. In the near future, this place will become a new "safe water tank" in Chengdu. The "Ten Regulations on Water Control in Chengdu" are clearly implement drinking water safety protection projects, and promote the construction of Lijiayan's "second water source". The so-called second water source is to ensure that the central urban area of Chengdu's water supply security provides at least 30 days of emergency water source protection. At present, Chengdu's central urban area depends on the Dujiangyan Water Conservancy Project for water supply. The water supply source is single, the level of emergency protection is low, and the ability to resist risks is poor. Once the upper reaches of the Minjiang River (Dujiangyan above the head of the canal) or problems with water supply channels, urban water supply will face huge risks.

Through document review, this study further identifies and summarizes the influencing factors of the Lijiayan Reservoir project construction process, with the goal of completing the project construction. Finally, an influence factor system composed of 11 factors from the five aspects: Social, economic, technological, capacity resources and ecological environment builds a model of influencing factors of construction management risk.

\subsection{Social Aspect}

\subsubsection{Risks of Changes in National Strategic Guidelines and Policies}

There will be differences in guidelines and policies in different periods. For example, the occurrence of some large emergencies such as COVID-19 in 2020 will directly affect the country's handling of the same incident. The changes in construction specifications and policies for reservoir projects cause risks that affect the construction process (Marked as P1).

\subsubsection{The Construction Party's Risk of Changes to the Infrastructure Planning}

Over time, after being exposed to emerging construction cases, the construction unit may have new plans and views on the project, which will affect the planning and arrangements made by the construction unit at the beginning, and some changes may affect the construction party's technology barriers and so on. For example, during the construction of a reservoir, the construction party may propose the use of new technologies or the difficulty of construction management that may be caused by the update of infrastructure planning (Marked as P2).

\subsubsection{Risk of Public Opinion}

Due to the need for resettlement in the construction of the reservoir, the lack of communication and handling measures by the construction party, and the non- 
cooperation of the masses during the construction process, the risk of public opinion may be triggered (Denoted as P3).

\subsection{Economic Aspect}

\subsubsection{Risk of Economic Loss Caused by Construction Injury Accidents}

Injury accidents are prone to occur during the construction process, which may result in economic losses due to damage of mechanics or the early results of the project, even casualties, regardless of their size (Denoted as P4).

\subsubsection{Turnover Risk of the Capital Chain}

The construction party did not receive the advance payment from the proprietor in time, or the construction party did not pay the labor service fee on time, which caused the workers to strike (Marked as P5).

\subsubsection{Risk of Construction Production Costs}

The market price of the materials when the construction party bids differ greatly from the actual construction time. For example, the construction of a reservoir needs to use cement and steel bars with sufficient waterproof and corrosion resistance capabilities (Denoted as P6).

\subsection{Technical Aspects}

\subsubsection{Satisfaction Degree Risk of Engineering Construction Technical Requirements}

Due to factors such as water pressure, the treatment of the wall and the bottom of the reservoir during the construction of it, the construction of the blocking dam, and other technical difficulties are higher (Recorded as P7).

\subsubsection{The Operator's Technical Proficiency, Knowledge of Quality and the Risk of His Physical Condition}

The technical proficiency and quality perception of the first-line operators selected by the construction party directly influence the quality of the project, and the physical condition of the operator will affect the completion of the project task. For example, when construction progresses to the side wall of the reservoir dam, workers are required to perform high-altitude operations. The degree of standardization of workers' operations and the psychological factors of workers facing high altitudes may affect the quality of the project (Denoted as P8).

\subsection{Capacity Risk}

\subsubsection{The Construction Party's Human Resources and Financial Resource Management Ability Risk}

Whether the construction team's labor team and management team have sufficient qualifications, the stability of their operations and financial management capabilities, and whether they meet the needs of the project scale. This aspect is also important.

The materials required for reservoir construction, the risks of mechanical supply and storage, and the characteristics of reservoir construction determine 
the transportation of materials during the construction process, and the difficulty of storage is greater than that of housing construction projects (Marked as P9).

\subsubsection{Construction Period Management Risk}

In the event of severe weather or unexpected events, the management of the construction period becomes more difficult, and it is very likely that the actual engineering efficiency does not match the plan or even a serious deviation (Denoted as $\mathrm{P} 10)$.

\subsection{Ecological Environment}

The risk of the impact of construction is on the ecological environment. The impact of building slag generated during construction on the environment; the risk of whether the losses caused by the inundation of the reservoir can be better dealt with in the construction, after the large-scale reservoir project is completed, the scenic spots in the reservoir area will be inundated, and whether better measures can be taken during the construction to reduce the inundation losses, the economic damage brought is as low as possible, and the proper degree of the treatment process will inevitably affect the construction cost, and there are many risks (Denoted as P11).

Through the above analysis, the construction management risk influencing factor system is shown in Figure 1.

\section{Research Methods}

The completion of the specified work in the engineering project will form a set

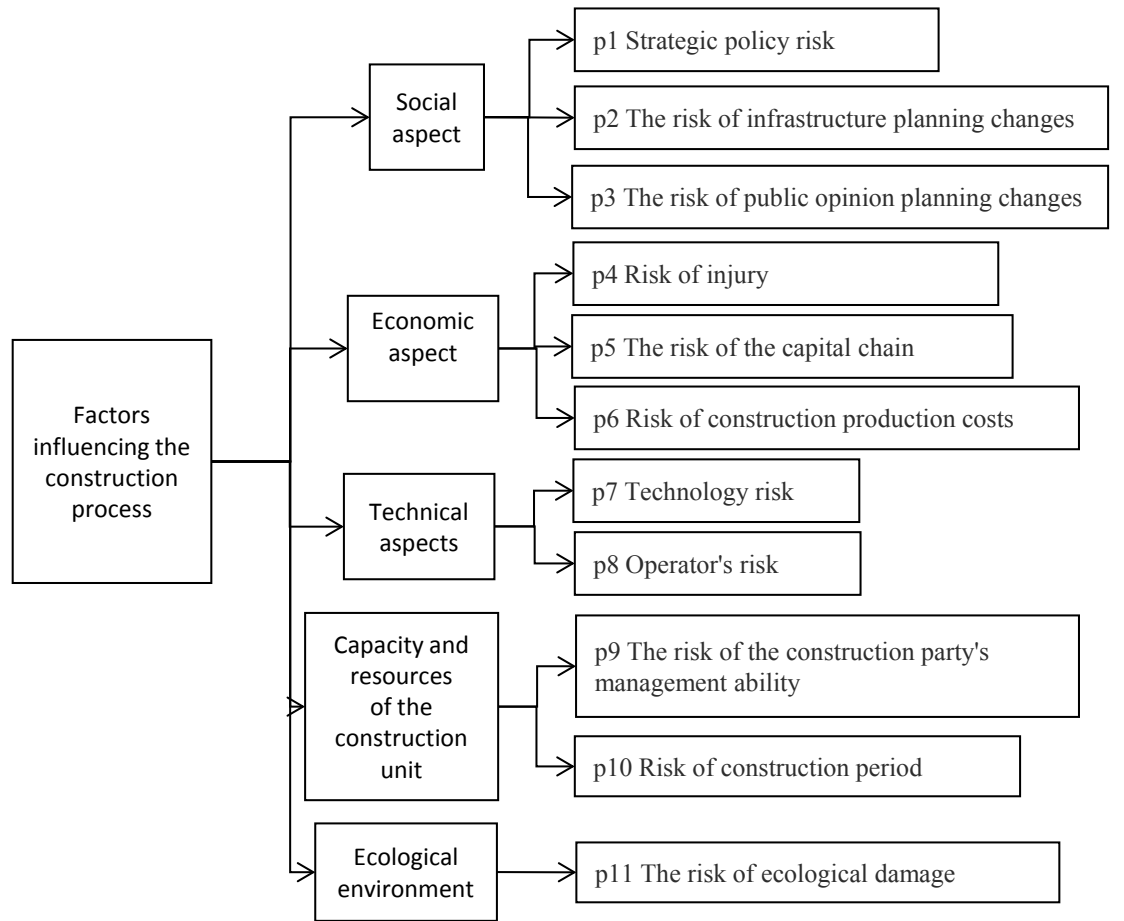

Figure 1. Risk influencing factor system of reservoir construction management. 
of specific systems in advance. The system is composed of many units, and there is a certain relationship between the units. To study a system, we must first understand this relationship, that is, we must first understand the structure of the system. The structural model of the system focuses on revealing the qualitative structure of the geometry or topology of it, without being entangled in the algebraic description or quantitative and statistical properties of the model. It is an objective model used to show the relationship between the various units of the system. Through this model, a complex system can be decomposed into a clear multi-level hierarchical structure. This paper analyzes the Lijiayan Reservoir project case through the above explained structure model and constructs the corresponding multi-level hierarchical structure model.

\section{Research Process and Results}

\subsection{Build the Structural Model}

Due to the demand for water resources development, the scale of reservoirs in Western China is getting larger and larger, and construction should be supplemented by a safer and more reliable construction management system. After the review of the literature and the relevant experts, the system structure of the risk factors affecting the construction management of the reservoir project was determined.

\subsection{Ask Questions and Identify Elements, Concretize the Conceptual Model}

Searching for construction management cases in multiple similar projects and analyzing the causes and consequences of each risk event, 11 risk factors that may be encountered during the construction of the reservoir project are determined, which are recorded as elements P1 - P11.

\subsection{Build Adjacency Matrix}

Let A denote the adjacency matrix. The adjacency matrix reflects the one-time arrival relationship between the elements and only reflects the direct arrival relationship. The expression used is Boolean algebra, that is, the relationship between 0 and 1, as shown in Figure 2.

\subsection{Calculate the Reachability Matrix}

Let $A_{1}=A+I, A_{2}=(A+I)_{2}, \ldots, A_{i}=(A+I)_{i}, I$ is the identity matrix, if $A_{1} \neq$ $A_{2}, A_{2} \neq A_{3}, \ldots, A_{r-1} \neq A_{r}, \mathrm{~A}_{\mathrm{r}}=A_{r+1}$, then $M=A_{r}$ is the reachable matrix. Operation rules: $0+0=0,0+1=1,1+1=1,1 \times 1=1$. The concrete matrix is shown in Figure 3.

\subsection{Decompose the Structure Matrix and Get a Multi-Level Hierarchical Structure Diagram}

The structure matrix is shown in Figure 4. According to the structure matrix, an advance set and a reachable set are established: 


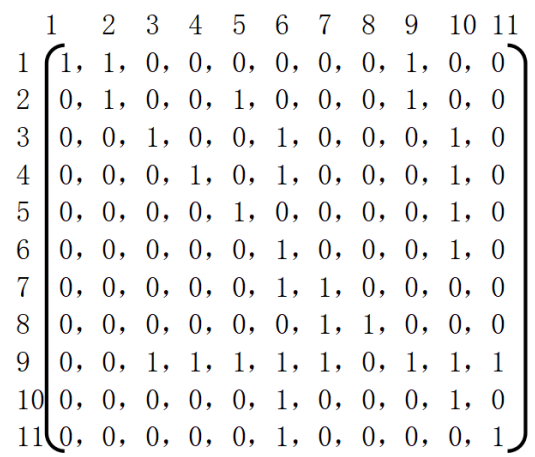

Figure 2. Adjacency matrix.

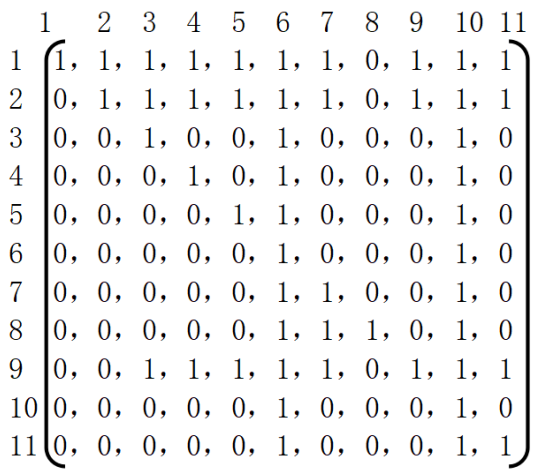

Figure 3. Reachable matrix.

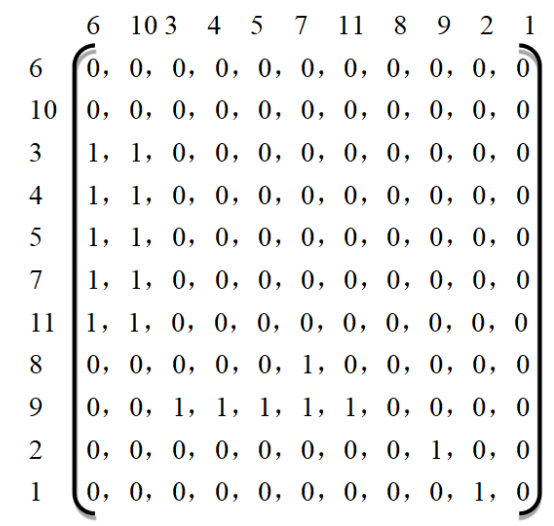

Figure 4. Structure matrix.

$$
\begin{aligned}
& R\left(P_{i}\right)=\left\{P_{j} \in P \mid m_{i j}=1\right\} \\
& S\left(P_{i}\right)=\left\{P_{j} \in P \mid m_{i j}=1\right\}
\end{aligned}
$$

$R\left(P_{i}\right)$ Reachable set: the row elements corresponding to all numbers 1 in the $\mathrm{S}_{\mathrm{i}}$-th column of the reachable matrix;

$S\left(P_{i}\right)$ Antecedent set: the column elements corresponding to all numbers 1 in the $S_{i}$-th row of the reachable matrix;

$L_{j}=\left\{P_{i} \in P \mid R\left(P_{i}\right) \cap S\left(P_{i}\right)=R\left(P_{i}\right)\right\}$, It can be seen that the element in $L_{j}$ is the highest level in the current classification. 


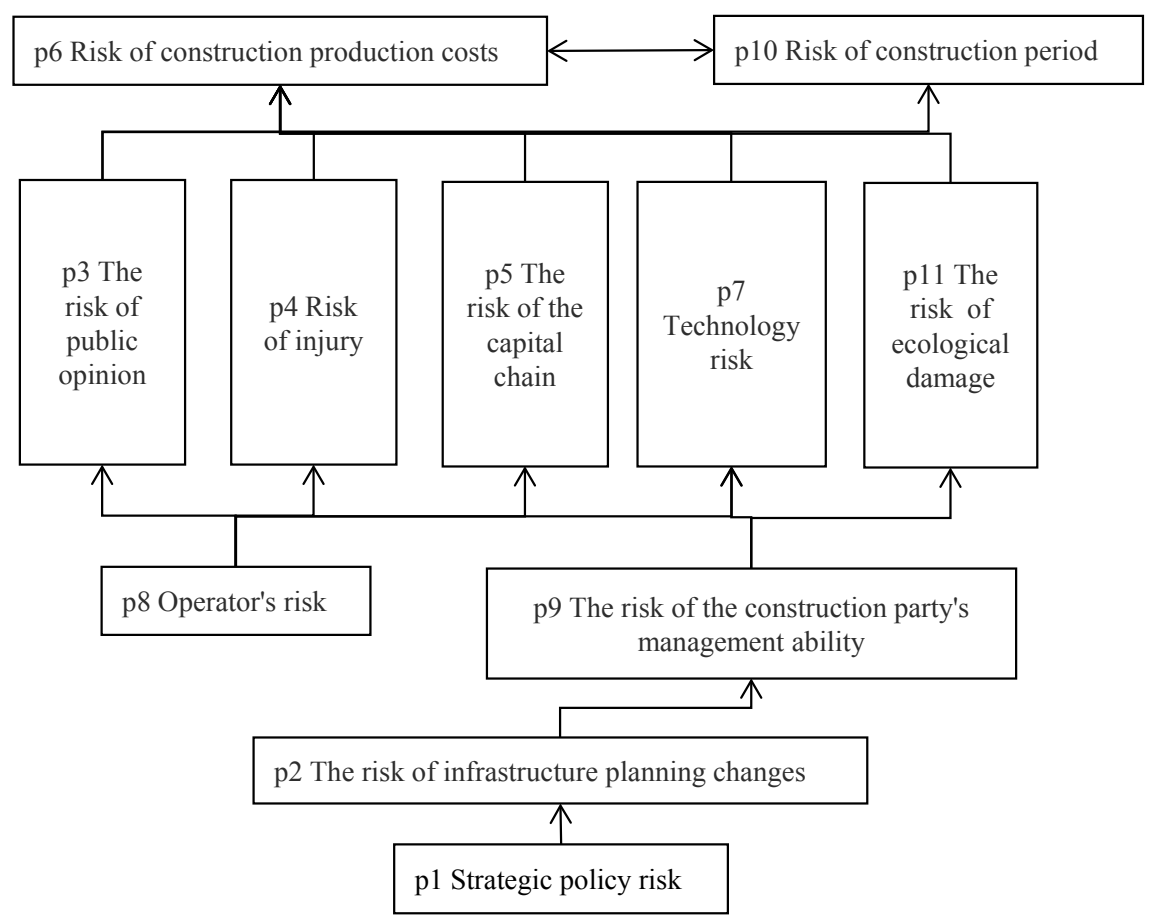

Figure 5. Multi-level hierarchical structure diagram.

By sub-regional and hierarchical processing of the above-mentioned reachable matrix, the relationship between the various factors that have an impact on the overall goal, which is, the construction goal of the reservoir project is obtained, the main factors and secondary factors, direct or indirect factors, are shown in Figure 5.

\subsection{Research Result}

According to the hierarchical structure division of the Interpretation Structure Model (ISM), the risk factors affecting construction management are divided into five classes and four levels (see Figure 5). The first level is the surface impact, there are two factors including construction production cost risk (P6) and construction period risk (P10). The second level is the middle-level impact, including the leader's public opinion risk (P3), injury accident risk (P4), capital chain risk (P5), technical risk (P7), ecological environment damage risk (P11), operator risk (P8) and the construction party's management ability risk (P9) a total of 7 factors. The third level is the in-depth impact, including the risk of infrastructure planning changes (P2) factors. The fourth level is the root impact, including strategic policy risk (P1) factors.

\section{Research Conclusions and Outlook}

\subsection{Conclusions}

This paper identifies 11 risk factors that affect the construction management of the reservoir project on the basis of reference to the previous literature. The relationship between the factors is processed through the ISM (interpretation struc- 
ture model) method. Now the research results are analyzed, and the following are obtained in conclusion:

1) Strategic policy risk is the most fundamental and critical risk element that affects construction management. Strategic guidelines and policies are a series of codes of conduct summarized by a country or an industry after judging its overall development trend, which is compulsory and timeliness. Strategic guidelines and policies have a significant impact on the construction party's planning changes, which in turn have a greater impact on the construction party's management work, and ultimately determine whether there will be various risk events that affect the construction period and cost during the process.

2) Infrastructure planning change has an important and deep impact on the control of the overall risk in the construction stage, the different changes of infrastructure planning bring different test degrees to the management ability of the construction party, and the strength of the management ability of whom will further affect the direction of the economic, technical, ecological, injury accident and public opinion risk that may occur on the way of the reservoir project under construction. From how a small process is implemented to how the entire reservoir is operated, it must be combined with current policies and regulations. If a construction company wants to obtain reasonable and legal benefits on the basis of controlling the overall risk, the premise is to carefully analyze the current strategy. Plan construction details according to policies.

3) During the construction of the reservoir project, the construction unit's management ability is reflected in its ability to identify possible risks in the five aspects of "human, machine, material, law and environment", which will affect the construction progress and cost, and ultimately affect the implementation effect of the entire project. Among them, the construction party can do a good job of public opinion research and plan the response measures in advance to solve the impact of the risk on the progress; the occurrence of injury accidents can be suppressed through rigorous three-level education before construction and thorough safety inspection during construction; the construction unit shall pay correct attention to the advance payment receipt in accordance with relevant regulations to ensure that the construction progress will not be affected by the shortage of funds; strengthening the training of the front-line operators of the project, and seizing all possible opportunities to improve the technical ability of the construction enterprises can greatly reduce the technical risks to a great extent; caring for the ecological environment is the theme of the era, and it is also the social responsibility of every people, strengthen the education and training of green behaviors, when the construction plan is selected, the risk of ecological and environmental damage can be dealt with on the premise of ecological priority.

4) The above conclusions obtained from the ISM model are almost consistent with the results studied by relevant scholars through hierarchical analysis, demonstrating the credibility of the methods used in this paper; but ISM is able to express the relationship of the influencing elements more clearly and distinguish 
the essence of the problem, exploring the essence of the problem is fundamental to completely solving the problem and controlling the risks.

\subsection{Outlook}

The research method in this paper may be combined with other evaluation models to further avoid the shortcomings of the ISM model, which needs more study afterward.

\section{Conflicts of Interest}

The authors declare no conflicts of interest regarding the publication of this paper.

\section{References}

[1] Dong H. and Liu F.M. (2020) Construction Management Risks and Prevention Strategies of Construction Projects. Construction Technology Development, 47, 40-41.

[2] Xu, X.L. and Liu, L.B. (2018) Exploration and Analysis of Construction Safety Risk Assessment and Management of Construction and Installation Engineering. Development Orientation of Building Materials, 16, 44-45.

[3] Wu, Y. (2021) The Current Situation and Future Development Direction of Road and Bridge Construction Technology. Science and Technology and Innovation, 98-99.

[4] Peng, P., Guo, H.L. and Fang, D.P. (2018) Research on Risk Source Identification and Countermeasures for Super High-Rise Building Construction. Construction Technology, 47, 16-23.

[5] Ding, Y. and Tian, Y.F. (2019) Research on Construction Quality and Safety Risk Assessment of Prefabricated Buildings. Construction Economy, 40, 80-84.

[6] Li, S.C. and Yang, G.S. (2014) AHP-Based Construction Safety Management Risk Control Strategy. Automation Instrumentation, 35, 25-28+31

[7] Duan, Y.H., Zhou, S.Y., Guo, Y.B. and Wang, X. (2020) Safety Risks and Strategies of Prefabricated Construction Based on SEM. Journal of Civil Engineering and Management, 37, 70-75+121.

[8] Yang, S.l., Huang, H.p., Liu, W. and Liu, L. (2019) Safety Risk Assessment of Prefabricated Building Construction Based on Structural Entropy Weight and Modified Evidence Theory. Safety and Environmental Engineering, 26, 143-149+153.

[9] Wu, X., Chang, C.G. and Yan, X. (2019) Safety Risk Decision of Prefabricated Building Construction Based on Particle Swarm Algorithm. Science Technology and Engineering, 19, 304-310.

[10] Hua, W.J., Zhou, T.J., Zhai, Y., Ni, J.X. and Wang, H.F. (2020) Safety Risk Assessment Method of Construction Site Based on ANP-FUZZY. Journal of Xi'an University of Architecture and Technology (Natural Science Edition), 52, 912-917.

[11] Liang, P., Liu, C. and Liang, S. (2021) Research on Construction Safety Risk Management from the Perspective of Big Data. Chongqing Architecture, 20, 32-34.

[12] Zhai, R., Zhang, Y.N. and Zhong, R. (2016) Building Construction Safety Risk Assessment System and Its Weight Based on AHP and VPRS. Journal of Civil Engineering and Management, 33, 109-114+120.

[13] Yang, L.Q., Li, S.R. and Jia, B. (2013) Construction Safety Risk Assessment Based on Binary Decision Diagram. System Engineering Theory and Practice, 33, 1889-1897. 